\title{
Assessment of floating plastic debris in surface water along the Seine River
}

Johnny Gasperi, Rachid Dris, Tiffany Bonin, Vincent Rocher, Bruno Tassin

\section{Introduction}

Over the last 60 years, the production of plastic has increased tremendously from 1.7 to 288 million tons (PlasticsEurope, 2013). Since 1970, many official studies and reports have warned of the pollution of marine environments by plastic litter and its subsequent environmental impacts; such publications have suggested that river and land-based sources are significant contributors (Andrady, 2011; Barnes et al., 2009; Carpenter et al., 1972; Cole et al., 2011; Derraik, 2002; Rech et al., 2014; UNEP, 2009). Plastics may originate from either voluntary or involuntary dumping, urban discharges and surface runoff. Once introduced into rivers, plastic debris may sink, be deposited on river banks and/or undergo transfer to the marine environment. Plastic debris may also be fragmented from photodegradation or, to a lesser extent, from mechanical action (Williams and Simmons, 1996). Due to the original size and the multiple fragmentation in the environment of plastics items, their survey must therefore be addressed according to a continuous size scaling, i.e. from nano- and micro-plastics $(<5 \mathrm{~mm})$ to macroplastics ( $>5 \mathrm{~mm}$ ) over extensive spatial and temporal integrative series (Arthur et al., 2009).

In raising questions about the origin and risk posed by plastic litter, some studies have investigated its abundance and nature in freshwater resources. Most of this research has focused on the U.S. Great Lakes or alpine lakes (Eriksen et al., 2013; Imhof et al., 2013; Mendoza and Evans, 2013), though a few have concentrated on rivers. Field work on the Danube (Lechner et al., 2014), Thames (Morritt et al., 2014), Tamar (Sadri and Thompson, 2014) and Los Angeles Rivers (Moore et al., 2011) is now available. In the U.S., Moore et al. (2011) used a variety of nets $(<1 \mathrm{~mm}$ mesh size) to evaluate plastic mass emissions in the Los Angeles and San Gabriel Rivers. By extrapolation over a 72-h period, the authors reached an approximate figure of 2.3 billion plastic objects and fragments, which correspond to roughly 30 tons. For the Thames River (U.K.), Morritt et al. (2014) investigated the submerged plastic items intercepted by eel fyke nets anchored to the river bed. For this study, a total of 8490 submerged plastic items were intercepted during a relative short sampling period. Using manta net $(300 \mathrm{~mm}$ mesh size), Sadri and Thompson (2014) observed for Tamar river plastics in a variety of forms and sizes and microplastics $(<5 \mathrm{~mm})$ comprised $82 \%$ of the debris. Authors reported that the most abundant types of plastic were polyethylene $(40 \%)$, polystyrene $(25 \%)$ and polypropylene. For the Danube, Lechner et al. (2014) used stationary driftnets over a 2-year period (2010-2012) to estimate the plastic flow being conveyed by the Danube to the Black Sea at 4.2 tons a day. More recently, data on anthropogenic riverine litter along river banks in Chile were also reported (Rech et al., 2014).

In spite of their significant contributions, these works have not considered floating plastic debris, mainly as a result of methodological choice, sampling difficulties and/or the plastic size 
category being targeted. A visual inspection of floating debris in rivers reveals low abundance, as well as a random spatial distribution, thus leading to inherent sampling difficulties. A floating debris assessment is actually quite difficult to perform and therefore requires a broad temporal integrative sampling approach. Failure to consider floating debris can lead to a significant underestimation of plastic mass loads exported by rivers. In assuming that a major share of

microplastics originate from the fragmentation of macroplastics and moreover that floating debris is expected to be more sensitive and exposed to photodegradation (Barnes et al., 2009), these debris must be investigated in order to address the overall issue of plastics in the environment.

In collaboration with the Parisian public sanitation service (SIAAP), this study was designed to evaluate the quantity and quality of floating plastic debris flowing down the River Seine within the Paris metropolitan area. The Seine catchment is heavily exposed to the impacts of intense human activity, given the high urban density within the Paris zone (12 million population). The floating debris intercepted by an expansive regional network of debris-retention booms has been analyzed as part of this study. The originality of these results lies in the comprehensive evaluation of floating plastic debris at a very large spatial and temporal scale.

\section{Materials and methods}

\subsection{Site description and sampling approach}

The Seine catchment drains an area of approximately $32,000 \mathrm{~km}^{2}$ from the river's headwaters to Paris and combines intense anthropogenic pressures with a very limited dilution factor for the river, due to its low mean flow rate $\left(350 \mathrm{~m}^{3} \mathrm{~s}^{-1}\right.$ in Paris proper). The Paris sewer network is a combined one, leading to discharges of combined sewer overflows (CSO) during wet weather periods (Gasperi et al., 2012). To avoid any visible pollution in rivers, the SIAAP has deployed a network of floating debris-retention booms since 1990. This network comprises 26 booms, i.e., 21 on the Seine and 5 on the Marne Rivers (the latter being one of the Seine's major tributaries upstream of Paris, Fig. 1). On the Seine, booms are distributed along a 77-km stretch and their interception width varied between 5 and $15 \mathrm{~m}$. Booms are anchored close to river banks (left or right) to allow the barge traffic. Each boom is cleared once a week using cleaner boats equipped with a conveyor belt, a coarse shredder and several garbage dumpsters. Practically, debris are extracted using the conveyor belt, are crushed and finally disposed in the garbage dumpster. Based on 6 years of monitoring (2008-2013), the total average mass of extracted floating debris amounts to 1937 tons (1591-2564 tons, SIAAP database, Table 1). 

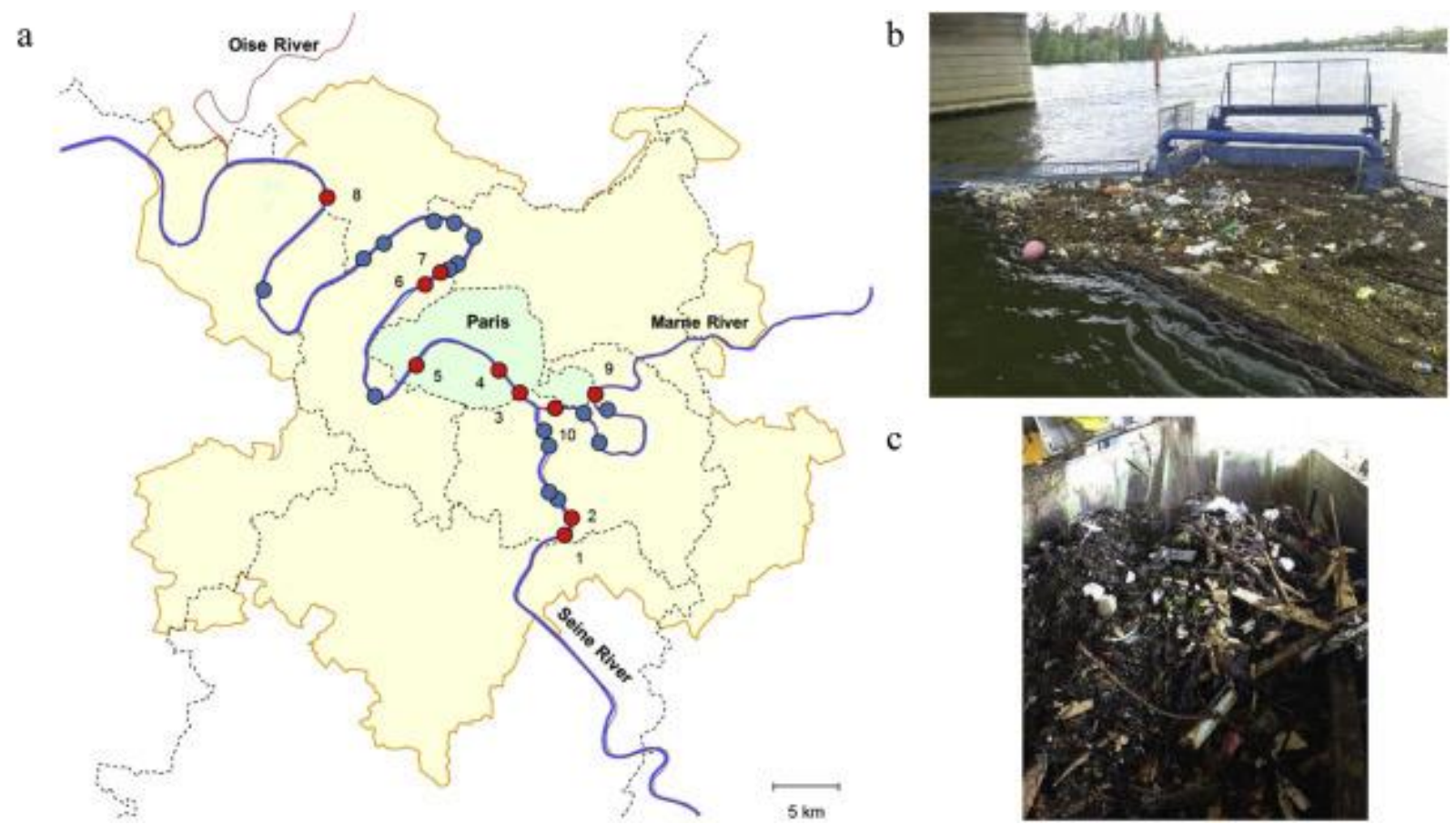

Fig. 1. (a) The network of floating booms in Paris (with the studied booms shown in red), (b) a picture of a floating boom, (c)an example of floating debris collected by the boom. (For interpretation of the references to colour in this figure legend, the reader is referred to the web version of this article).

Table 1. Estimated tonnage of floating plastic debris intercepted by the SIAAP boom network.

\begin{tabular}{lllll} 
& & Total floating debris & \multicolumn{2}{l}{ Hypotheses $^{\mathbf{a}}$} \\
& & $\mathbf{0 . 8 \%}$ & $\mathbf{1 . 4 \%}$ & $\mathbf{5 . 1 \%}$ \\
2008 & 2157 & 17 & 30 & 110 \\
2009 & 1591 & 13 & 22 & 81 \\
2010 & 1636 & 13 & 23 & 83 \\
2011 & 1706 & 14 & 24 & 87 \\
2012 & 1969 & 16 & 28 & 100 \\
2013 & 2564 & 21 & 36 & 131 \\
Mean & 1937 & 15 & 27 & 99
\end{tabular}

a

Three hypotheses corresponding to the minimum, mean and maximum mass percentages of plastic in floating debris.

$\mathrm{b}$

Total floating debris intercepted by booms annually (SIAAP data). 
Field campaigns were conducted from April to July 2014: River Seine flow varied between 80 and $290 \mathrm{~m}^{3} \mathrm{~s}^{-1}$. A total of 10 booms were considered (Fig. 1), down and upstream of Paris. For boom no. 3, two duplicate campaigns were carried out. After a homogenization of the garbage dumpster using a gripper onboard, approx. $10 \mathrm{~kg}$ of crushed debris were collected in the garbage dumpster (one dumpster per boom) using five $2 \mathrm{~kg}$-subsamples. These subs-samples were manually collected. In laboratory, debris was manually sorted by three categories: vegetal debris, plastic debris, and other debris including glass and aluminum cans. For plastic items, all debris greater than $5 \mathrm{~mm}$ were considered, dried and weighted. The mass percentage of plastic debris as a proportion of total floating debris (in \%) was hence estimated.

\subsection{Identification of plastic items}

All plastic fragments collected from the $10 \mathrm{~kg}$ of crushed debris were analyzed using a Fourier transform infrared spectrometer coupled to an Attenuated Total Reflectance accessory (FTIRATR). The wave number ranged between 4000 and $1000 \mathrm{~cm}^{-1}$, and 4 scans were performed with a $4 \mathrm{~cm}^{-1}$ resolution. The identification of plastic debris was performed by applying spectroscopy software to the spectrum and using the polymer database (Sadtler ATR of Polymers). Six categories, imported from the resin identification coding system, were identified: polyethylene terephthalate (PET), polyethylene low and high density (PE $(\mathrm{LD}+\mathrm{HD})$ ), polyvinylchloride (PVC), polypropylene (PP), polystyrene (PS), and other materials $(\mathrm{O})$. Then, the distribution $(\%)$ of the floating plastic debris in the various polymers categories is estimated.

\subsection{Estimation of the plastic loads intercepted by booms}

Based on the total annual mass of debris intercepted by booms on both rivers on the 2008-2013 period (SIAAP data, Table 1) and the mass percentage of plastic debris as a proportion of total floating debris (in \%) observed in this study, the tonnage of floating plastic debris intercepted by the SIAAP boom network was estimated. Therefore, three hypothesizes corresponding to the minimal, mean and maximal mass percentages of plastic found in booms were considered.

\section{Results and discussion}

\subsection{Percentage of plastic debris and litter composition}

Regardless of the boom considered, vegetal debris was predominant and represented between $92.0 \%$ and $99.1 \%$ of total floating debris by weight. Natural and manufactured wood and all sorts of plants were found. The "other" floating debris category accounted for $0.0 \%-6.8 \%$ of the totals. The mass percentage of plastic debris ranged between $0.8 \%$ and $5.1 \%$, with an average value of $1.4 \%$ (Fig. 2). As reported by Morritt et al. (2014) for submerged plastics, a significant proportion of these plastics in the present study consisted of food wrappers/containers and plastic cutlery; relatively few plastic bags were observed. The 
predominance of food wrappers/containers and plastic cutlery is probably due to recreational activities, with direct or indirect dumping into the Seine in addition to runoff and CSO discharges. On the other hand, and contrary to Morritt et al. (2014), no tobacco packaging/wrappers or sanitary towel components were found. These differences in litter composition may be related to: i) the methodological approaches and devices deployed for floating and submerged items; ii) their different mechanical behavior in interaction with the river dynamics (river vs. estuary area) and iii) likely differences in way of life including waste management practices. To date, only Rech et al. (2014) has provided information on the composition of plastic litter (for 4 Chilean rivers). Accordingly to their own classification, these authors indicated that persistently buoyant items, especially plastics followed by PS, were the most abundant litter items, yet they did not provide any more detailed information on the types of plastic found. A coarse comparison can also be made with the 2013 results of a local organization (Mal de Seine, http://maldeseine.free.fr/OSPAR.html) about $100 \mathrm{~km}$ downstream of Paris. In adapting the Guideline for Monitoring Marine Litter on Beaches in the OSPAR Maritime Area and in collecting all plastic debris along a 117-m stretch of river bank, a total of 17,000 items were collected, including 5274 polystyrene objects, 2981 cotton buds, 1660 caps, 1136 food containers and 3988 confectionary packages. Sanitary products, including towels and back strips, were also observed ( 88 items).

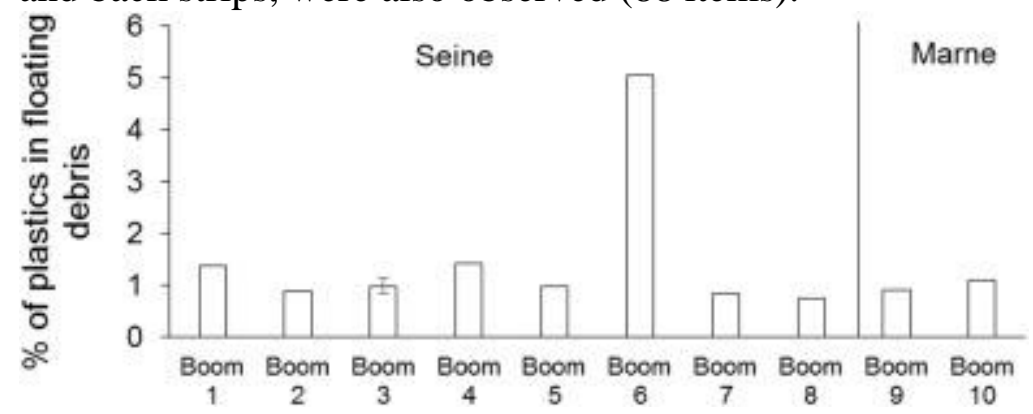

Fig. 2. Mass percentage of plastic debris as a proportion of total floating debris (\%).

Except for boom no. 6, the percentage of plastic debris was quite homogenous across all sites, only varying from $0.8 \%$ to $1.4 \%$. For boom no. 3 , the mass percentage variability was estimated at $1.0 \% \pm 0.2 \%$ ( 2 campaigns and 4 replicates corresponding to the error bar in Fig. 2). From a global perspective, no clear difference in plastic loads could be found between the upstream and downstream sections of the River Seine. The high percentage of plastic for boom no. 6 is correlated with its immediate proximity to the largest CSO outfall within the Paris metropolitan area (Gasperi et al., 2012) and with a CSO discharge of about $100,000 \mathrm{~m}^{3}$ that occurred prior to sampling.

\subsection{Nature of the plastic debris}

The composition of floating plastic debris is depicted in Fig. 3. Most plastic items intercepted by booms contain PP $(35.2 \% \pm 21.6 \%$, average value \pm standard deviation) or PE (LD + HD) $(26.0 \% \pm 14.6 \%)$, and to a lesser extent PET $(20.7 \% \pm 20.1 \%)$. The remaining resin categories account for $10.8 \% \pm 12.3 \%$ for PS and $7.4 \% \pm 11.4 \%$ for O. Interestingly, low density polymers 
such as PP $\left(0.920 \mathrm{~g} \mathrm{~cm}^{-3}\right)$, PE $\left(0.920 \mathrm{~g} \mathrm{~cm}^{-3}\right)$ and PS $\left(1.040 \mathrm{~g} \mathrm{~cm}^{-3}\right)$ but also denser polymer such as PET $\left(1.380 \mathrm{~g} \mathrm{~cm}^{-3}\right)$ are observed for plastic debris suggesting that their transport is influenced by factors other than density alone. In the Tamar estuary, Sadri and Thompson (2014) also reported for debris $>5 \mathrm{~mm}$ that PE, PP and to a lesser PS were the most abundant types of floating debris but also observed denser polymers.

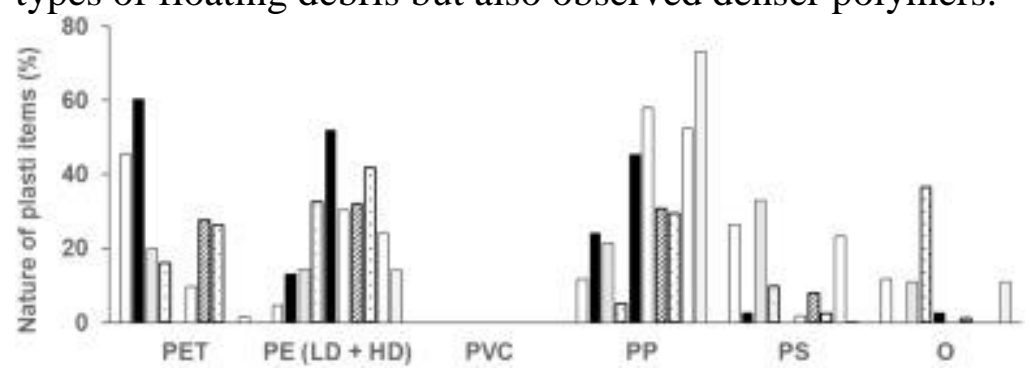

Fig. 3. Type of floating plastic debris (in \%) (From left to right: booms 1-10).

The plastic composition varied significantly from one boom to the next; and no spatial trend was observed. Difference of plastic distribution could be mainly linked to local and discontinuous inputs (including CSO discharges), differences in the local hydrodynamic conditions along the rivers leading to different behaviors of the floating items, as well as the methodological but opportunistic approach.

As previously quoted by Sadri and Thompson (2014), the resin pattern observed for plastic debris is roughly similar to plastic production for packaging uses (PlasticsEurope, 2013). Various packaging applications actually account for the largest single sector within the plastics industry (39.4\%). The absence of PVC items intercepted by these booms is quite surprising as PVC represents $10.7 \%$ of the European plastics demand. It could be probably explained by both i) their higher density avoiding their buoyancy $\left(1380 \mathrm{~g} \mathrm{~cm}^{-3}\right)$, and ii) their uses and the probable routes leading to rivers. PVC is, in fact, mainly used in the building and construction sector, and it can be reasonably assumed that few routes are likely available for construction products to enter rivers.

\subsection{Evaluation of floating plastic debris mass loads conveyed by the River Seine}

At the annual scale and based on the median hypothesis, between 22 and 36 tons (mean value: 27 tons) of floating plastic debris were intercepted annually by the SIAAP boom network on both rivers between 2008 and 2013 (Table 1). Although the plastics targeted in this study differ from those investigated by Lechner et al. (2014), this 27-ton/year figure is much lower than the plastic being conveyed to the North Sea by the Danube, i.e. 1500 tons a year. It should be borne in mind that the targets and populations in these basins differ significantly, i.e. about 12 million for the Seine basin vs. 88 million for the Danube. Given the local Paris basin population (12 million) and considering the mean values from three hypotheses, the mass of floating plastic debris per inhabitant per year is estimated at between 1.3 and $8.2 \mathrm{~g}$. In comparison, the input per inhabitant on the Danube basin might reach approx. $17.4 \mathrm{~g}$ a year. This rough comparison 
supports the finding of a large and not insignificant contribution of floating plastic debris among the total plastic input.

Within the actual context of the European Marine strategy framework directive as the litter reduction plan, the current issue is now to establish the link between the debris intercepted by booms (about 27 tons per year for both rivers, mean value) and the total amount of floating debris conveyed by both rivers. To date, this link cannot be more precisely established since the capture efficiency of the booms was not determined. This capture efficiency could be nevertheless relatively high since both the high barge traffic and river meanderings sweep floating debris close to the river bank and enhance the debris interception by booms. A lower capture efficiency could be expected during floods. Plastic debris sinks along river banks may occur but could be limited since river banks are extremely artificial along this $77 \mathrm{~km}$ stretch. A part of floating plastics may also sink and be transferred downstream in mid water or in river floor, but it is unknown.

\section{Conclusions}

By investigating floating debris at a large regional scale, using a deployed boom network, this study is one of the first to deliver reliable information on the quantity and quality of floating plastic debris conveyed by rivers in urban areas.

Plastic debris represented between $0.8 \%$ and $5.1 \%$ of total debris by weight. A significant proportion of these plastics consisted of food wrappers/containers and plastic cutlery most likely associated with recreational activities. Most plastic items are made of PP, PE and, to a lesser extent, PET. According to a median hypothesis, between 22 and 36 tons of plastics are intercepted annually by the booms, thus confirming the major inputs of land-based sources. Such data could contribute to a first evaluation of floating plastic inputs conveyed by rivers and released into oceans. Subsequently, data on the total amount of plastic conveyed by rivers in mid water (Morritt et al., 2014) and river floor, and not only in surface and sub-surface have to be provided to estimate the total river inputs. The correlations between plastic loads and certain river basin features (i.e. population, density, land use, waste management practices) must also be investigated. The amount of plastic debris per inhabitant per year may provide an insightful measure. These data might also help with the implementation of new more stringent regulations regarding plastic litter, with the aim of drastically reducing ocean plastic pollution.

\section{Acknowledgments}

The authors gratefully acknowledge the SIAAP authority, and more especially Julien Pouillaude, as well as the EMCC Company for their valuable technical support throughout this study.

\section{References}

A.L. Andrady Microplastics in the marine environment Mar. Pollut. Bull., 62 (2011), pp. 1596-1605 
C. Arthur, Baker, Bamford Proceedings of the international research workshop on the occurrence, effects and fate of microplastic Marine debris T.M (Ed.), NOS-OR\&R-30 (2009) Tacoma, WA, USA

D.K.A. Barnes, F. Galgani, R.C. Thompson, M. Barlaz Accumulation and fragmentation of plastic debris in global environments Phil. Trans. Royal Soc. B Biol. Sci., 364 (2009), pp. 1985-1998

E.J. Carpenter, S.J. Anderson, G.R. Harvey, H.P. Miklas, B.B. Peck Polystyrene spherules in coastal waters Sci. New. N.Y, 178 (1972), pp. 749-750

M. Cole, P. Lindeque, C. Halsband, T.S. Galloway Microplastics as contaminants in the marine environment: a review Mar. Pollut. Bull., 62 (2011), pp. 2588-2597 Article

J.G.B. Derraik The pollution of the marine environment by plastic debris: a review Mar. Pollut. Bull., 44 (2002), pp. 842-852 Article

M. Eriksen, S. Mason, S. Wilson, C. Box, A. Zellers, W. Edwards, H. Farley, S. Amato Microplastic pollution in the surface waters of the Laurentian Great Lakes Mar. Pollut. Bull., 77 (2013), pp. 177-182 $\underline{\text { Article }}$

J. Gasperi, S. Zgheib, M. Cladière, V. Rocher, R. Moilleron, G. Chebbo Priority pollutants in urban stormwater: part 2-Case of combined sewers Water Res., 46 (2012), pp. 6693-6703 $\underline{\text { Article }}$

H.K. Imhof, N.P. Ivleva, J. Schmid, R. Niessner, C. Laforsch Contamination of beach sediments of a subalpine lake with microplastic particles Curr. Biol., 23 (2013), pp. R867R868 Article

A. Lechner, H. Keckeis, F. Lumesberger-Loisl, B. Zens, R. Krusch, M. Tritthart, M. Glas, E. Schludermann The Danube so colourful: a potpourri of plastic litter outnumbers fish larvae in Europe's second largest river Environ. Pollut., 188 (2014), pp. 177-181 Article

L.M.R. Mendoza, C.Y. Evans Plastics are Invading Not Only the Ocean But Also the Great Lakes Abstracts of Papers of the American Chemical Society, vol. 245 (2013)

C. Moore, G. Lattin, A. Zellers Quantity and type of plastic debris flowing from two urban rivers to coastal waters and beaches of Southern California J. Integr. Coast. zone Manag., 11 (2011), pp. 65-73

D. Morritt, P.V. Stefanoudis, D. Pearce, O.A. Crimmen, P.F. Clark Plastic in the Thames: a river runs through it Mar. Pollut. Bull., 78 (2014), pp. 196-200 Article

PlasticsEurope Plastics - the Facts 2013, an Analysis of European Latest Plastics Production, Demand and Waste Data Plastics Europe, Association of Plastic Manufacturers, Brussels (2013), p. 40

S. Rech, V. Macaya-Caquilpan, J.F. Pantoja, M.M. Rivadeneira, D. Jofre Madariaga, M. Thiel Rivers as a source of marine litter-a study from the SE Pacific Mar. Pollut. Bull., 82 (2014), pp. 66-75 $\underline{\text { Article }}$ 
S.S. Sadri, R.C. Thompson On the quantity and composition of floating plastic debris entering and leaving the Tamar Estuary, Southwest England Mar. Pollut. Bull., 81 (2014), pp. 55-60 $\underline{\text { Article }}$

UNEP N. UNEP (Ed.), Marine Litter: a Global Challenge (2009), p. 232 http://www.unep.org/pdf/unep_marine_litter-a_global_challenge.pdf

A.T. Williams, S.L. Simmons The degradation of plastic litter in rivers: implications for beaches J. Coast. Conserv., 2 (1996), pp. 63-72 